Bitterman, N . \& Shalev, I. (2005) Profile of graduates of Israeli medical schools in 1981-2000: educational background, demography and evaluation of medical education programs. Israel Medical Association Journal, 7, 292-297.

Burra, P., Kalin, R., Leichner, P., et al (1982) The ATP 30 - a scale for measuring medical students' attitudes to psychiatry. Medical Education, 16, 31-38.

Feifel, D . Moutier, C. Y. \& Swerdlow, N. R. (1999) Attitudes toward psychiatry as a prospective career among students entering medical school. American Journal of Psychiatry, 156, 1397-1402.

Israel Ministry of Health Statistics (2003) Statistics from http:/ / w w w. health.gov.il/dow nload/docs/units/meida/ manpower2003/7 11.pdf. Last accessed 7 July 2005.

Malhi, G. S., Parker, G. B., Parker, K., et al (2002) Shrinking away from psychiatry? A survey of Australian medical students' interest in psychiatry. Australian and New Z ealand Journal of Psychiatry, 36, 416-423.

$\mathrm{N}$ ielsen, A. C. 3rd \& Eaton, J. S. Jr (1981) Medical students attitudes about psychiatry. Implications for psychiatric recruitment. Archives of General Psychiatry, 38, 1144-1154.

Sierles, F. S., Dinwiddie, S. H., Patroi, D., et al (2003) Factors affecting medical student career choice of psychiatry from 1999 to 2001. Academic Psychiatry, 27, $260-268$.

Weissman, S. H., Haynes, R. A., Killian, C. D., et al (1994) A model to determine the influence of medical school on students' career choices: psychiatry, a case study. Academic Medicine, 69, 58-59.

Zimny, G. H. \& Sata, L. S. (1986) Influence of factors before and during medical school on choice of psychiatry as a specialty. American Journal of Psychiatry, 14, 77-80.

\title{
Attitudes to psychiatry: a comparison of Spanish and US medical students
}

\section{Guillem Pailhez ${ }^{1}$, Antonio Bulbena² and Richard Balon ${ }^{3}$}

${ }^{1}$ Centres Assistencials Dr Emili Mira i López, Departament de Salut Mental, Diputació de Barcelona, Av. Prat de la Riba 171, 08921 Santa Coloma de Gramenet, Barcelona, Spain, email: pailhezvg@diba.es

'Institut d'Atenció Psiquiàtrica: Salut Mental i Toxicomanies, Hospital del Mar (IMAS), Barcelona, Spain

${ }^{3}$ Wayne State University, Detroit, Michigan, USA

\section{The present} tendency in daily practice towards managed care has changed psychiatric training, and now students may consider psychiatrists as mere psychopharmacologists. here is a growing concern in many countries over the low recruitment into psychiatry among medical graduates. This has led to studies that aim: (1) to study the attitudes of medical students towards psychiatry, (2) to determine factors that influence such attitudes, (3) to assess the possible causes of this low recruitment and (4) to try to change students' views of psychiatry during their medical education to improve recruitment.

In the U nited States a negative attitude towards psychiatry or the psychiatrist's role has been observed among medical students at the start of their freshman year (Feifel et al, 1999); however, on completion of their psychiatric training it seems that the opinions of students are now improving (Balon et al, 1999) in comparison with attitudes that were prevalent 25 years ago ( $\mathrm{N}$ ielsen \& Eaton, 1981).

$O$ ver the past 20 years studies in the $U$ nited States ( $N$ ielsen \& Eaton, 1981; Balon et al, 1999; Sierles et al, 2003a,b) and in the U nited Kingdom (Brockington \& Mumford, 2002) have reported that the percentage of students choosing psychiatry as their future specialty has decreased steadily, although other evidence suggests a small increase recently among U S students, from 3.5\% in 1999 to 4.5\% in 2003 ( $\mathrm{N}$ ational Resident Matching Program, 2003). The recent increase may be due to a change in opinions to wards the field, although this may represent only a partial explanation (Balon et al, 1999).
Factors that affect the proportion of students contemplating a career in psychiatry have been divided into extrinsic (e.g. national trends, geographical region) and intrinsic factors (e.g. the quality of psychiatric education). In the USA it seems that local and regional extrinsic factors were not associated with an increase in the proportion of students choosing psychiatry (Sierles et al, 2003a). This emphasises that the quality of educational programmes could be one of the most important influences on students' attitudes to psychiatry. Experiences such as students' contact with psychiatric patients (Singh et al, 1998), the quality of training (Lee et al, 1995) and the prestige of the local psychiatric department (Sierles, 1982) emerge as influential aspects of psychiatric education. Sierles et al (2003b) have discussed concerns about future recruitment into the psychiatric profession in the United States. 0 ne of these concerns is the graduating seniors' suboptimal satisfaction with their psychiatry clerkships. Another is that clerkship directors in psychiatry, when compared with those in other specialties, tend to perceive more that managed care reduces the quality of clinical medical education. The present tendency in daily practice towards managed care has changed psychiatric training, and now students may consider psychiatrists as mere psychopharmacologists. Thus the profession may not fulfil students' expectations that psychiatry would be more oriented tow ards psychotherapy (Balon et al, 1999). 


\section{Attitudes to psychiatry}

In order to gain a broader view of the process of recruitment, we compared the attitudes to psychiatry of Spanish and US medical students (Pailhez et al, 2005). We chose these groups because a comparison between two different countries with different teaching approaches to psychiatry could help us gain a broader perspective on the complex process of recruitment. We recorded the opinions of 151 students who had completed psychiatry at the end of their fourth year. 0 ur survey was based on responses to a 33-item questionnaire, using a crosssectional design. D ata on US students were obtained from the study by Balon et al (1999), whose questionnaire explo red the attitudes of medical students tow ards psychiatry in six areas: (1) overall merits of psychiatry, (2) efficacy, (3) role definition and functioning of psychiatrists, (4) possible abuse and social criticism, (5) career and personal reward and (6) factors specific to the medical school.

We found that many Spanish students felt that psychiatry was not an expanding frontier of medicine. However, Spanish students regarded psychiatry as more scientific and precise than other specialties $(72.9 \%$ of the Spanish sample endo rsed this view, compared with $56.1 \%$ of the US sample).

More Spanish than US students agreed that a psychiatric consultation could be useful for medical or surgical patients. How ever, about a third of Spanish students $(37.1 \%)$ said that most psychiatrists are not logical thinkers, compared with $17.9 \%$ of the US sample. Furthermore, the Spanish students were largely of the opinion that psychiatrists have no more authority and influence than other mental health professionals; that they are too apologetic when teaching psychiatry; and that psychiatrists abuse their legal power to hospitalise patients against their will. Finally, Spanish students expressed a greater preference than did U S students for a style of psychiatric practice that was both more biological and more attentive to the patient's psychological problems.

Regarding career choice, Spanish students tended to believe that psychiatry has low social prestige. H owever, they seemed to be subject to fewer additional external pressures when making their choice of specialty than were students in the United States; these pressures included the opinion of their family (14.9\% in Spain versus $25.3 \%$ in the $U$ nited States), friends (20.4\% in Spain versus $33.0 \%$ in the United States) and fellow students (34.0\% in Spain versus 41.5\% in the U nited States).

Spanish students had a worse opinion of the quality of psychiatry teaching $(48.3 \%$ of students in Spain believed it to be good, compared with $73.8 \%$ in the U nited States). (These questions referred to both the quality of the theoretical lessons and the psychiatry rotation.) They also described receiving less encouragement to enter psychiatry as a profession than did students in the U nited States $(49.6 \%$ in Spain versus $69.1 \%$ in the U nited States), but reported more respect for psychiatry among non-psychiatric staff $(71.7 \%$ in Spain versus $54.5 \%$ in the U nited States).

\section{Recruitment}

In general, Spanish students' views of psychiatry were positive, as were those of the US students in the study by Balon et al (1999). However, comparisons revealed differences in responses to some questions relating to the bio-psychosocial concept of illness, salary, social pressure and respect from non-psychiatric staff. The number of students choosing psychiatry as their future career was $6 \%$ in our study. This percentage is higher than the $4.5 \%$ currently reported in the U nited States.

Some US authors have tried to elucidate the possible causes of low recruitment: first, there is a large influence of biological psychiatry in the specialty nowadays; second, there are lower income prospects compared with other specialties; third, psychiatry, psychology, social work and primary care medicine overlap in the treatment of patients (Sierles \& Taylor, 1995; Balon et al, 1999). 0 ther causes of negative attitudes could be the negative social pressure exerted by colleagues and non-psychiatric staff in the medical schools ( $\mathrm{N}$ ielsen \& Eaton, 1981), or the inability of psychiatry to change society through medicine (Balon et al, 1999). Approximately $14 \%$ more Spanish students than US students felt that psychiatry is too biological $(32.6 \%$ in Spain versus $18.5 \%$ in the $U$ nited States) and that, on average, psychiatrists make as much money as most other doctors $(62.4 \%$ in Spain versus $48.7 \%$ in the United States). More believed that their friends $(66.0 \%$ in Spain versus $58.4 \%$ in the U nited States) and non-psychiatric staff $(71.7 \%$ in Spain versus $54.5 \%$ in the United States) would respect their decision to become a psychiatrist. These factors affect recruitment in a very complex way, and the explanations of the difference in attitudes of Spanish and US students are speculative. In the U nited States students do not seem to have the same reasons as Spanish students for negative attitudes to psychiatry in these specific respects.

The uptake of a residency position in Spain is determined by an official examination; the overall number of positions is determined by the Ministry of $\mathrm{H}$ ealth. $\mathrm{O}$ nly those students who complete the 4 years of residency after the entrance examination get the specialist degree. $O$ ver the last decade, the Ministry of $\mathrm{H}$ ealth has increased the number of psychiatry positions by $33 \%$. In the year 2002/03, out of a total of 5496 medical residency positions, $2.9 \%$ were in psychiatry, making it the eighth most available specialty. D espite this increase in the number of positions, $51.7 \%$ of the students from our study with an interest in psychiatry after their fourth year of medical school could not enter the specialty.

In this respect, the recruitment process has not presented particular difficulties for the training of psychiatrists in Spain. The number of positions offered yearly by the Ministry of $\mathrm{H}$ ealth depends on the capacity of the accredited training centres, the national budget
Spanish students were largely of the opinion that psychiatrists have no more authority and influence than other mental health

professionals; that they are too apologetic when teaching

psychiatry; and that psychiatrists abuse their legal power to hospitalise patients against their will. 
available and social demand. Therefore, in contrast with US students, who are guaranteed a psychiatry position, Spanish medical students may regard psychiatry as a more worthwhile specialty because of the competition for training places.

From the 1950s to the mid-1970s, studies in the U nited States showed that students considered psychiatry more unscientific and imprecise and to have less prestige than nowadays. How ever, recruitment then was at its highest (C astelnuovo-Tedesco, 1967; Zimet $\&$ H eld, 1975). Students seemed to make their choice while being very aware of the specialty's weak points. Paradoxically, when students' opinions are more critical, recruitment in both Spain and the U nited States seems to rise, probably because being more critical leads to a better understanding and stronger desire to choose the specialty. $0 \mathrm{r}$ could it be that recruitment has nothing to do with attitudes to psychiatry after all?

\section{References}

Balon, R., Franchini, G. R., Freeman, P. S., et al (1999) Medical students' attitudes and views of psychiatry: 15 years later. Academic Psychiatry, 23, 30-36.

Brockington, I. F. \& Mumford, D. B. (2002) Recruitment into psychiatry. British Journal of Psychiatry, 180, 307-312.

Castelnuovo-Tedesco, P. (1967) How much psychiatry are medical students really learning? Archives of General Psychiatry, 16, 668-675.
Feifel, D., Moutier, C. Y. \& Swerdlow, N. R. (1999) Attitudes toward psychiatry as a prospective career among students entering medical school. American Journal of Psychiatry, 156, 1397-1402.

Lee, E. K., Kaltreider, N. \& Crouch, J. (1995) Pilot study of current factors influencing the choice of psychiatry as a specialty. American Journal of Psychiatry, 152, 10661069

National Resident Matching Program (2003) Match Results, 1999-2003. Washington, DC: N ational Residents Matching Program. See http://www.nrmp.org/. Last accessed 26 August 2005.

$\mathrm{N}$ ielsen, A. C. 3rd \& Eaton, J. S. Jr (1981) Medical students' attitudes about psychiatry. Implications for psychiatric recruitment. Archives of General Psychiatry, 38, 1144-1154.

Pailhez, G., Bulbena, A., Coll, J., et al (2005) Attitudes and views on psychiatry: a comparison between Spanish and U.S. medical students. Academic Psychiatry, 29, 82-91.

Sierles, F. (1982) Medical school factors and career choice of psychiatry. American Journal of Psychiatry, 139, 1040-1042.

Sierles, F. S. \& Taylor, M. A. (1995) Decline of US medical student career choice of psychiatry and what to do about it. American Journal of Psychiatry, 152, 1416-1426.

Sierles, F. S., Dinwiddie, S. H., Patroi, D., et al (2003a) Factors affecting medical student career choice of psychiatry from 1999 to 2001. Academic Psychiatry, 27, 260-268.

Sierles, F. S., Yager, J. \& Weissman, S. H. (2003b) Recruitment of U.S. medical graduates into psychiatry: reasons for optimism, sources of concern. Academic Psychiatry, 27 $252-259$

Singh, S. P., Baxter, H., Standen, P., et al (1998) Changing the attitudes of 'tomorrow's doctors' towards mental illness and psychiatry: a comparison of two teaching methods. Medical Education, 32, 115-120.

Zimet, C. N . \& Held, M. L. (1975) The development of views of specialties during four years of medical school. Journal of Medical Education, 50, 157-166.

\title{
Some Australian reflections on problems with recruitment into the profession of psychiatry
}

\author{
Bruce J. Tonge
}

Professor and Head, Department of Psychological Medicine, Monash University, Monash Medical Centre, Clayton, Victoria 3168, Australia, email: bruce.tonge@med.monash.edu.au

Both studies found that psychiatry was regarded overall as the least attractive career option in the field of medicine and that the students held negative and prejudicial views about the practice of psychiatry and its patients. sychiatry has probably always been the least attractive of the medical specialties. The choice of psychiatry as a career has been consistently low in the English-speaking world over the past 50 years (British Medical Journal, 1973; Feifel et al, 1999; Brockington \& Mumford, 2002). O ver the past decade there has probably been a further decline in the proportion of medical graduates choosing to train in psychiatry (Sierles \& Taylor, 1995; Feifel et al, 1999).

\section{The situation in Australia: an international comparison}

In Australia over the past several years it has been increasingly difficult to fill available psychiatry training positions. A critical factor in recruitment is the attitude medical students develop towards psychiatry as a specialty and as a possible career choice.

In 2003 an Australian study was published regarding the attitudes of 655 new medical students towards psychiatry as a career choice (Malhi et al, 2003). This study replicated the findings of a study of 221 new students attending three medical colleges in the southwest U nited States (Feifel et al, 1999). Both studies found that psychiatry was regarded overall as the least attractive career option in the field of medicine and that the students held negative and prejudicial views about the practice of psychiatry and its patients.

The Australian study gathered questionnaire information from 655 , of a possible 1032 , first-year medical students attending a mix of six undergraduate-entry 